\title{
Beckwith-Wiedemann syndrome: a demonstration of the mechanisms responsible for the excess of transmitting females
}

\author{
Céline Moutou, Claudine Junien, Isabelle Henry, Catherine Bonaïti-Pellié
}

\begin{abstract}
Beckwith-Wiedemann syndrome (BWS) is often associated with embryonal tumours (nephroblastoma, adrenocortical carcinoma, hepatoblastoma, and rhabdomyosarcoma). Several pedigrees have been reported strongly suggesting autosomal dominant inheritance and an excess of transmitting females was noticed in these families. We confirmed this excess using 19 published pedigrees and showed that this excess was for two reasons: first, reduced fecundity in affected males compared to females in a ratio of $1: 4 \cdot 6$, and, second, a smaller risk of being affected in a ratio of $1: 3$ for subjects having inherited the gene from their father. These latter findings suggest genomic imprinting. Furthermore, considering these results together with other observations, such as the parental origin of the 15p15.5 duplication and the existence of uniparental disomy in some sporadic cases, we propose that overgrowth in BWS patients and malignant proliferation in associated tumours reflect an imbalance between paternal and maternal alleles.
\end{abstract}

The Beckwith-Wiedemann syndrome (BWS) is characterised by exomphalos, macroglossia, gigantism, visceromegaly, and a high incidence of embryonal tumours including nephroblastoma (WT), adrenocortical carcinoma, hepatoblastoma, and rhabdomyosarcoma (RMS). Although most cases are sporadic, several pedigrees have been reported strongly suggesting autosomal dominant inheritance with incomplete penetrance and variable expressivity. ${ }^{1}$ Partial $11 \mathrm{p}$ trisomies having in common a duplication of region $11 \mathrm{p} 15.5$ have been observed in a few cases. ${ }^{2-8}$ The assignment of a locus for familial BWS to $11 \mathrm{p} 15.5$ was further confirmed by linkage analysis..$^{910}$ Interestingly, the event triggering malignant proliferation in associated tumours, WT ${ }^{1112}$ and $\mathrm{RMS},{ }^{13}$ is a loss of $11 \mathrm{p}$ maternal alleles, often restricted to the same $11 \mathrm{p} 15.5$ region. Some authors have hypothesised a sex dependent mode of transmission for familial BWS because affected subjects seem to be born more often to transmitting mothers than to transmitting fathers. ${ }^{914}$ Two possible mechanisms can account for the excess of transmitting mothers. On one hand, there could be some higher selection against male than female gene carriers leading to a differential fecundity according to the sex of the gene carriers. Another possible explanation is that the risk for a gene carrier of being affected is higher when the deleterious gene is maternally inherited. Although these hypotheses are sometimes considered as true statements, we would like to emphasise that they have never been proven by statistical analysis. In this paper, we test these two hypotheses by analysing 19 informative, previously published families.

\section{Materials and methods \\ DATA}

The data used in this analysis were the published pedigrees where a proband was specified. ${ }^{1910}$ In some pedigrees, subjects were reported as 'possibly affected' and since diagnostic criteria may vary among authors these subjects were removed from the analysis in order to avoid classification errors. Finally, 40 sibships could be used for the analysis because the transmitting parent could be identified with certainty, either because he or she was affected or had affected relatives.

\section{DIFFERENTIAL FECUNDITY OF GENE CARRIERS}

\section{ACCORDING TO SEX}

Since gene carriers will never transmit the gene if they have no offspring, the probability that a woman or a man would be recognised as a carrier clearly depends on their mean number of offspring, and is obviously nil if he or she has no offspring. To test an equal probability of transmitting the gene in both sexes, we tried to answer two questions. (1) Do male carriers have as many offspring as female carriers? This was tested by comparing, using the rank sum test, the mean number of offspring of male and female transmitters, that is, gene carriers (affected or not), who had at least one offspring. (2) Is there some selection against affected men which prevents them from having children? This question was 
Table 1 Differential fecundity among subjects carrying the BWS gene according to sex and disease status.

*Including dead subjects.

\begin{tabular}{lcccccc}
\hline & \multicolumn{2}{c}{ Women } & & \multicolumn{2}{c}{ Men } \\
\cline { 2 - 3 } & Affected & Unaffected & & Affected & Unaffected \\
\hline No of subjects & 3 & - & & 15 & - \\
$\quad$ Without offspring* & 11 & 27 & & 3 & 11 \\
$\quad$ With offspring & 43 & 120 & & 12 & 34 \\
No of offspring & & & &
\end{tabular}

$$
\mathrm{L}_{1}=\left(\begin{array}{c}
s-1 \\
\mathrm{r}-1
\end{array}\right) \mathrm{p}^{\mathrm{r}-1}(1-\mathrm{p})^{\mathrm{s}-\mathrm{r}}
$$

where $s$ is the size of the sibship, $r$ the number of affected children, and $p$ the segregation ratio. Note that this correction is the maximum when the ascertainment mode is unknown.

(2) Truncate selection for other sibships in the pedigrees selected through at least one affected subject:

$$
\mathrm{L}_{2}=\frac{\left(\begin{array}{l}
\mathrm{s} \\
\mathrm{r}
\end{array}\right) \mathrm{p}^{\mathrm{r}}(1-\mathrm{p})^{\mathrm{s}-\mathrm{r}}}{1-(1-\mathrm{p})^{\mathrm{s}}}
$$

answered by comparing the proportion of af fected males and females who had offspring. This comparison cannot be made among unaffected gene carriers since obligate carriers are always recognised through at least one affected (or carrier) offspring.

\section{SEGREGATION ANALYSIS OF SIBSHIPS WITH A GENE CARRIER PARENT}

To test whether the risk of being affected is higher for a subject who has inherited the gene from his mother, we performed segregation analysis of sibships with a carrier and compared the segregation ratio $p$ (which is half the penetrance in the case of dominant inheritance) among subjects born to gene carrier women to that among subjects born to gene carrier men.

Since we used published family data and not families belonging to series collected using precise sampling criteria, there is a selection bias toward families containing multiple cases. Therefore, our segregation ratio is an overestimation. The classical correction for ascertainment ${ }^{15}$ is obviously not sufficient to remove this bias, and the segregation ratio estimated here is not valid for the whole population. However, we are not interested in the absolute value of this risk of morbidity, but in the relative value according to the sex of the transmitting parent. Since the bias should be independent of the sex of the transmitting parent, it should not affect our conclusions on the differential risk.

We used classical segregation analysis ${ }^{15}$ with maximum likelihood (ML) estimation, taking into account the way the sibship had been selected.

(1) Single selection for the sibships with the proband:

Table 2 Number of sibships used for segregation analysis according to author,

\begin{tabular}{|c|c|c|c|c|}
\hline \multirow{2}{*}{ Author } & \multirow{2}{*}{$\begin{array}{c}\text { Transmitting } \\
\text { parent }\end{array}$} & \multicolumn{3}{|c|}{ Type of selection } \\
\hline & & Single & Truncate & Complete \\
\hline \multirow[t]{2}{*}{ Niikawa et al ${ }^{1}$} & Mother & $\begin{array}{c}11 \\
(25 / 15)\end{array}$ & $\stackrel{6}{(11 / 17)}$ & $\begin{array}{c}4 \\
(4 / 26)\end{array}$ \\
\hline & Father & $\begin{array}{c}2 \\
(2 / 3)\end{array}$ & $\begin{array}{c}1 \\
1 / 2)\end{array}$ & $\begin{array}{c}4 \\
4 \\
(0 / 12)\end{array}$ \\
\hline Koufos et al ${ }^{9}$ & Mother & $\begin{array}{c}(2 / 3) \\
0\end{array}$ & $\begin{array}{c}(1 / 2) \\
2 \\
(3 / 4)\end{array}$ & $\begin{array}{c}(0 / 12) \\
4 \\
(7 / 9)\end{array}$ \\
\hline \multirow[t]{2}{*}{ Ping et $a l^{10}$} & $\begin{array}{l}\text { Father } \\
\text { Mother }\end{array}$ & $\begin{array}{l}0 \\
1\end{array}$ & $\begin{array}{l}0 \\
1\end{array}$ & $\begin{array}{l}0 \\
1\end{array}$ \\
\hline & Father & $\begin{array}{c}(2 / 0) \\
0\end{array}$ & $\begin{array}{c}(1 / 1) \\
1 \\
(1 / 3)\end{array}$ & $\begin{array}{c}(4 / 3) \\
2 \\
(3 / 5)\end{array}$ \\
\hline Total & $\begin{array}{l}\text { Mother } \\
\text { Father }\end{array}$ & $\begin{array}{r}12 \\
2\end{array}$ & $\begin{array}{l}9 \\
2\end{array}$ & $\begin{array}{l}9 \\
6\end{array}$ \\
\hline
\end{tabular}
transmitting parent, and type of selection used.

In brackets, number of affected/unaffected offspring in these sibships.
(3) Complete selection for sibships not selected through an affected subject:

$$
\mathrm{L}_{3}=\left(\begin{array}{l}
\mathrm{s} \\
\mathrm{r}
\end{array}\right) \mathrm{p}^{\mathrm{r}}(1-\mathrm{p})^{\mathrm{s}-\mathrm{r}} .
$$

To test homogeneity of risk according to the sex of the carrier parent, we used the well known ML ratio property: if $L_{F}$ is the $M L$ of $p$ when the carrier parent is the father, $L_{M}$ the ML when the carrier parent is the mother, and $\mathrm{L}$ the $\mathrm{ML}$ for all sibships, then minus twice the natural logarithm of the $M L$ ratio $\mathrm{L} /\left(\mathrm{L}_{\mathrm{F}}+\mathrm{L}_{\mathrm{M}}\right)$ asymptotically follows a $\chi^{2}$ distribution with one degree of freedom.

\section{Results}

DIFFERENTIAL FECUNDITY AMONG CARRIERS

A simple counting of transmitting subjects showed 38 transmitting mothers and 14 transmitting fathers (table 1): the excess of transmitting mothers is highly significant $\left(\chi_{1}^{2}=11.07, \mathrm{p}<0.001\right)$.

Table 1 shows the number of gene carriers who had offspring and those who had no offspring in generations who could procreate, and the total number of offspring, according to sex and disease status of the transmitting parent. The mean number of offspring among those who had at least one child is 4.29 for women $(163 / 38)$ and 3.29 for men (46/14). This difference is not significant (rank sum test).

However, there is a significant excess in the proportion of affected males with no offspring, $0.83(15 / 18)$, compared to this proportion, 0.21 $(3 / 14)$, in affected females $\left(\chi^{2}{ }_{1}=9.88\right.$ [with correction for continuity], $p=0 \cdot 003)$. The affected males thus have a reduced probability of transmitting the deleterious gene in the ratio of the mean number of offspring of affected males $(12 / 18)$ and females (43/14), that is, $1: 4 \cdot 6$ $(0.67 / 3.07)$.

Thus, it appears that there is reduced fecundity among affected males, as a high proportion of them had no offspring, either because they died before they could procreate or had reduced fertility or ability to mate.

\section{SEGREGATION ANALYSIS}

Table 2 shows the number of sibships used for the analysis according to author, type of selection, and sex of transmitting parent.

The segregation ratio, as defined previously, was estimated to be 0.43 (SE 0.05) when the carrier parent is the mother, and 0.14 (SE 0.07) 
when the carrier parent is the father. Minus twice the logarithm of the maximum likelihood under the hypothesis of equal risk, obtained on the whole sample, is 94.53 . Minus twice the logarithm of the maximum likelihood obtained when the carrier parent is the mother and the father is 71.52 and 14.79 , respectively. This leads to the rejection of the hypothesis of equal risk $\left(\chi^{2}{ }_{1}=94.53-(71.52+14.79)=8.22\right.$, $\mathrm{p}<0.01$ ). Thus, the risk (and consequently the penetrance) is three times higher $(0 \cdot 43 / 0 \cdot 14)$ when the transmitting parent is the mother than the father.

\section{Discussion}

We have shown that the excess of transmitting mothers in families with Beckwith-Wiedemann syndrome has two reasons; first, reduced fecundity in affected males compared to females in the ratio of $1: 4 \cdot 6$, and, second, a smaller risk of being affected, in the ratio $1: 3$, for subjects having inherited the gene from their father. This is the first demonstration of these assertions.

Analysis of 174 published cases ${ }^{16}$ showed genitourinary abnormalities in $24 \%$ of patients with BWS. These abnormalities included clitoromegaly and cryptorchidism. The latter could account for the decreased fecundity in carrier males.

The inheritance of BWS and, in particular, the finding that offspring of male carriers are less often or less severely affected might be explained by genomic imprinting. There is evidence, mainly from studies done in mice, that the expression of certain genes differs according to whether they are inherited from the mother or from the father. Furthermore, there are reports suggesting that methylation of the regulatory regions of genes is associated with gene inactivation by transcriptional inhibition. The excess of obligate BWS carrier females compared to males is similar to findings in pedigrees with familial glomus tumours. This cancer predisposing disorder is transmitted almost exclusively through the paternal line. ${ }^{17}$ Preferential transmission by females in a BWS family led Koufos et $a l^{9}$ to suggest that the paternally transmitted allele at the BWS locus is always functionally inactivated (by imprinting); offspring are then only affected if they inherit a mutation from their mother. Moreover, to account for this observation, Aleck and Hadro ${ }^{18}$ proposed that BWS could be transmitted in a two step process involving first an unstable premutation and then a 'telomutation'. These hypotheses, however, do not fit with the following observations.

First, although the disease is preferentially transmitted through the maternal line, there are obvious cases of paternal transmission. An explanation could be that imprinting may vary from one cell to another and thus result in functional mosaicism. Alternatively, expression of the normal allele opposite the mutation could enhance or decrease the phenotype. Modifying genes which segregate in some families could influence the expression of the
BWS gene in a parental origin specific fashion analogous to the mutations Fused and Disorganised in the mouse. More likely, the expressivity and penetrance would depend on the type and number of cells that are allele specifically inactivated. ${ }^{19}$

Second, we examined the parental origin of the $11 \mathrm{p} 15.5$ region duplicated in patients trisomic for this region and displaying some features of BWS. Combining the published data $^{420}$ with additional published $\operatorname{cases}^{821}$ showed a significant difference in paternal transmission. In the 15 cases reported so far, the parental origin could be identified in 13. In one case with a de novo duplication and in 11 out of 12 cases of $11 \mathrm{p} 15.5$ trisomy owing to malsegregation of a parental rearrangement, the duplicated region was of paternal descent $(\mathrm{p}=0.003)$. As noted by Brown et $a l,{ }^{8}$ this finding is difficult to reconcile with the hypothesis of Koufos et al, ${ }^{9}$ since it is hard to explain why the duplication of a functionally inactive allele should have any phenotypic effect.

Third, using cloned DNA markers specific for the $11 \mathrm{p} 15.5$ region to determine the parental origin of chromosome 11 in eight sporadic cases, we found that probands in three informative families displayed uniparental paternal disomy. ${ }^{22}$

Whatever the function of the BWS gene, tumour suppressor or growth factor, and whatever the parental origin of the imprint, the different observations are apparently contradictory under a single locus hypothesis, but could be explained by the involvement of two (or more) closely linked genes. Alternatively, overgrowth in BWS patients and malignant proliferation in associated tumours may reflect an imbalance between paternal and maternal alleles.

1 Niikawa N, Ishikiriyama S, Takahashi S, et al. The Wiedemann-Beckwith syndrome: pedigree studies on five families with evidence for autosomal dominant inheritance with variable expressivity. Am f Med Genet 1986; 24:41-55.

2 Waziri M, Patil SR, Hanson JW, Bartley JA. Abnormality of chromosome 11 in patients with features of BeckwithWiedemann syndrome. $\mathcal{F}$ Pediatr 1983;102:873-6.

3 Turleau C, de Grouchy J, Chavin-Colin F, Martelli H, Voyer M, Charlas R. Trisomy $11 \mathrm{p} 15$ and BeckwithWiedemann syndrome: a report of two cases. Hum Genet 1984;67:219-21.

4 Aleck K, Williams J, Mongkolsmai C, Knight S, Taysi K. Partial trisomy $11 \mathrm{p}$ with interatrial septal aneurysm: case Partial trisomy $11 \mathrm{p}$ with interatrial septal aneurysm: case
report and literature review. Ann Genet (Paris) report and $1985 ; 28: 102-6$.

5 Journel H, Lucas J, Allaire C, et al. Trisomy $11 \mathrm{p} 15$ and Beckwith-Wiedemann syndrome: report of two new Beckwith-Wiedemann syndrome: report

6 Wales JKH, Walker V, Moore IE, Clayton PT. Bronze baby syndrome, biliary hypoplasia, incomplete BeckwithWiedemann syndrome and partial trisomy 11. Eur $\mathcal{J}$ Pediatr 1986;145:141-3.

7 Henry I, Jeanpierre M, Couillin P, et al. Molecular definition of the 11p15.5 region involved in Beckwith-Wiedemann syndrome and probably in predisposition to adrenocortical carcinoma. Hum Genet 1989;81:273-7.

8 Brown KW, Williams JC, Maitland NJ, Mott MG. Genomic imprinting and the Beckwith-Wiedemann syndrome. Am F Hum Genet 1990;46:1000-1.

9 Koufos A, Grundy P, Morgan K, et al. Familial Wiedemann-Beckwith syndrome and a second Wilms' tumor locus both map on $11 \mathrm{p} 15.5$. Am f Hum Genet 1989:44:711-9.

10 Ping AJ, Reeve AE, Law DJ, Young MR, Boehnke $M$, Feinberg AP. Genetic linkage of Beckwith-Wiedemann Fyndrome to 11p15. Am ₹ Hum Genet 1989;44:720-3.

11 Schroeder WT, Chao LY, Dao DD, et al. Non random loss of maternal chromosomes in Wilms' tumors. Am $\mathcal{f}$ Hum
Genet 1987;40:413-20.

12 Williams JC, Brown KW, Mott MG, Maitland NJ. Maternal allele loss in Wilms' tumour. Lancet 1989;i:283-4. 
13 Scrable H, Cavenee W, Ghavimi F, Lowell M, Morgan K, Sapienza C. A model for embryonal rhabdomyosarcoma tumorigenesis that involves genomic imprinting. Proc Natl Acad Sci USA 1989;86:7480-4.

14 Lubinsky M, Hermann J, Kossef AL, Opitz JM. Autosomal dominant sex dependent transmission of the WiedemannBeckwith syndrome. Lancet 1974;i:932.

15 Morton NE. Genetic tests under incomplete ascertainment. Am f Hum Genet 1959;11:1-16.

16 Sotelo-Avila C, Gonzales-Crussi F, Fowler JW. Complete and incomplete forms of Beckwith-Wiedemann syndrome: their oncogenic potential. $f$ Pediatr 1980 96:47-50.

17 Van der Mey AGL, Maaswinkel-Mooy PD, Cornelisse CJ, Schmidt PH, Van der Kamp JJP. Genomic imprinting in hereditary glomus tumours: evidence for a new genetic theory. Lancet 1989;ii:1291-4.
18 Aleck KA, Hadro TA. Dominant inheritance of Wiedemann-Beckwith syndrome: further evidence for transmission of "unstable premutation" through carrier women. Am f Med Genet 1989;33:155-60.

19 McGowan R, Cambell R, Peterson A, Sapienza C. Cellula mosaicism in the methylation and expression of hemizy gous loci in the mouse. Genes Dev 1989;2:1669-76.

20 Turleau C, de Grouchy J. Beckwith Wiedemann syndrome: clinical comparison between patients with and withou 11 p15 trisomy. Ann Genet (Paris) 1985;28:93-6.

21 Tonoki H, Narahara K, Matsumoto T, Niikawa N. Regional mapping of the parathyroid hormone gene (PTH) by cytogenetic and molecular studies. Cytogenet $\mathrm{Cel}$ Genet 1991;56:103-4.

22 Henry I, Bonaïti-Pellié C, Junien C. Uniparental paternal disomy in a genetic cancer-predisposing syndrome. Nature 1991;351:665-7. 